\title{
O USO DE REALIDADE AUMENTADA EM LIVROS IMPRESSOS: UMA EXPERIÊNCIA DE HIBRIDISMO ANALÓGICO E DIGITAL EM UM CONTEXTO EDUCACIONAL
}

\author{
PORTO ALEGRE/RS AGOSTO/2018

\begin{abstract}
Daiana Garibaldi da Rocha
- ULBRA e SAGAH - daiana1502@terra.com.br

Adriana Ferreira Cardoso

- Unisinos e SAGAH - adriadri81@hotmail.com
\end{abstract}

Tipo: Relato de Experiência Inovadora (EI)

Categoria: Métodos e Tecnologias

Setor Educacional: EDUCAÇÃO SUPERIOR

\begin{abstract}
RESUMO
A ação de aprender acontece, cada vez mais, em contextos híbridos e multimodais. Misturam-se $o$ ambiente físico e virtual, o digital e o analógico, bem como as tecnologias que intermedeiam o processo de aprendizagem. Aprende-se tanto por meio de uma aula presencial quanto via computador ou dispositivos móveis. O aprender torna-se resultado da interação do aluno com a tecnologia, de modo que há uma postura ativa em buscar significado para a experiência vivida. Mediante esse cenário, as tecnologias educacionais emergem como elementos facilitadores da aprendizagem. Inscrito no campo teórico das tecnologias digitais, este artigo apresenta um relato de experiência, com o objetivo de relatar o desenvolvimento de um recurso de Realidade Aumentada em um livro impresso da área da saúde, cujo propósito é ser um dos objetos de aprendizagem que compõe cursos da modalidade de Educação a Distância (EAD). As ferramentas teóricas são fornecidas por vários autores, sendo centrais Lilian Bacich (2015 e 2018), Adolfo Neto (2015) e Fernando Trevisani (2015), especialmente quanto ao conceito de hibridismo. Para o desenvolvimento técnico da realidade aumentada, buscamos o autor Ezequiel Roberto Zorzal (2011). E, por fim, no campo das competências, inspiramo-nos em conceitos de Antoni Zabala (2010) e Laia Arnau (2010). Apresentaremos 11 macroetapas que foram identificadas ao longo do desenvolvimento desta experiência e que mostram a complexidade do processo de construção da Realidade Aumentada. Nos ensaios finais colocamos em discussão a complexidade de produção das etapas de desenvolvimento, a necessidade de ter uma equipe multidisciplinar, mas ao mesmo tempo, as potencialidades que 0 recurso pode proporcionar para a aprendizagem do aluno EAD.
\end{abstract}

Palavras-chave: Realidade aumentada; competências; hibridismo.

\section{AGRADECIMENTOS}

AGRADECEMOS AO GRUPO A EDUCAÇÃO, UNIDADE DE NEGÓCIOS SAGAH PELA OPORTUNIDADE E APOIO PARA O DESENVOLVIMENTO DESTE ARTIGO. 


\section{INTRODUÇÃO}

A ação de aprender acontece, cada vez mais, em contextos híbridos e multimodais. Misturam-se o ambiente físico e virtual, o digital e o analógico, bem como as tecnologias que intermedeiam o processo de aprendizagem. Aprende-se tanto por meio de uma aula presencial quanto via computador ou dispositivos móveis. O aprender torna-se resultado da interação do aluno com a tecnologia, de modo que há uma postura ativa em buscar significado para a experiência vivida. Mediante esse cenário, as tecnologias educacionais emergem como elementos facilitadores da aprendizagem.

Entre as tecnologias passíveis de serem utilizadas em contextos educacionais, está a realidade aumentada (RA). Esse recurso é capaz de promover a coexistência entre 0 analógico (o físico) e o digital. Para Schlemmer (2014), "[...] no caso da realidade aumentada, o digital acrescenta informação à cena presencial física, [...] potencializando o conhecimento a respeito de objetos, lugares ou eventos (p. 77). Desta forma, mediante sua característica de aproximar a experiência virtual à realidade física, é grande o seu potencial pedagógico principalmente para a modalidade de Educação a Distância, pois permite uma interação entre conteúdo e aluno, ao mesmo tempo que garante a cientificidade e, assim, justifica-se ainda mais o seu uso em contextos educacionais.

Em relação ao objetivo, pretendemos, neste artigo, apresentar uma experiência de desenvolvimento do recurso de realidade aumentada (RA) em um livro impresso da área da saúde, mais especificamente do curso de nutrição, representando-se assim um ensaio híbrido entre o analógico e o digital ocorrido por meio dessa inserção. A ação foi desenvolvida por uma equipe multidisciplinar de uma empresa de soluções educacionais. A partir do relato, almejamos que este artigo possa mobilizar outras reflexões, outras formas de pensar e aplicar a experiência de realidade aumentada (RA) no âmbito educacional.

As ferramentas teóricas que nos auxiliarão durante este relato são fornecidas por autores tanto da área da educação como da área técnica de desenvolvimento tecnológico. Para o contexto do hibridismo, apoiamo-nos em Lilian Bacich, Adolfo Neto e Fernando Trevisani (2015). Para apoio quanto ao desenvolvimento técnico da realidade aumentada, buscamos o autor Ezequiel Roberto Zorzal (2011). E, por fim, no campo das competências, inspiramo-nos em conceitos de Antoni Zabala e Laia Arnau (2010).

Pensamos que compreender as etapas de desenvolvimento da RA como um processo metodológico que envolve etapas desde mais técnicas, como modelagem 3D, até pedagógicas, como a identificação do conteúdo mais relevante para a aplicação, pode 
nos fazer vislumbrar o próprio processo de ensino e aprendizagem com outros olhares, talvez mais contemporâneos e, quem sabe, ainda em transformação.

Apresentaremos a seguir nosso aporte teórico e as etapas que foram identificadas ao longo do desenvolvimento desta experiência e que mostram a complexidade do processo de construção da RA. Salientamos que o processo está dividido em macro e micro etapas, mas que, para este artigo, reduziremos o relato à exposição apenas das etapas em nível macro.

\section{INSPIRAÇÕES TEÓRICAS}

"O processo de aprendizagem é único e diferente para cada ser humano, e cada um aprende o que é mais relevante e que faz sentido para ele, o que gera conexões cognitivas e emocionais" (BACICH e MORAN, 2018, p. XV). Foi a partir desse pressuposto que a intenção de desenvolver RA surgiu em nossa equipe. Sabemos que estímulos diferentes proporcionam conexões diferentes para a aprendizagem e que tais motivadores mobilizam o desenvolvimento de novas competências nos alunos.

Nosso desafio durante a produção da RA foi buscar entender como transpor, para o aplicativo de RA, a experiência de vivenciar e desenvolver competências conceituais, já tradicionalmente aplicadas em livros, e a competência procedimental, de modo que o aluno pudesse conectar o conceito com a prática e vivenciá-lo. Como nos dizem Zabala e Arnau (2010),

[...] o conteúdo procedimental é aprendido quando os alunos thes atribuem sentido e significado, e isso é possível somente quando as atividades são conduzidas sobre conteúdos reais, o que significa, inevitavelmente, sua utilização sobre os objetos de conhecimento. (p. 48).

Olhar para as páginas de um livro e buscar excertos que podem se tornar exemplos "vivos" da aplicabilidade de conceitos anteriormente apresentados, para nós, sempre será o maior desafio, pois isso nos faz refletir sobre as competências que gostaríamos que nossos alunos desenvolvessem através de tal experiência. Nesse contexto, o conceito de competência no qual nos apoiamos "indica que as aprendizagens devem se realizar sempre de modo funcional e significativo, atribuindo sentido ao que se aprende" (ZABALA e ARNAU, 2010, p. 185).

No momento em que o aluno vivencia e realiza conexões entre o físico e o analógico, entre o real e o digital, entre o conceito e a sua aplicabilidade, entendemos que estamos 
Ihe proporcionando uma experiência híbrida de aprendizagem e lhe apresentando maneiras mais prazerosas e significativas de aprender. Desse modo, compreendemos como uma experiência híbrida aquela que oportuniza a mistura e a integração de áreas de conhecimento diferentes, em espaços e tempos distintos.

Como reforçam Bacich, Neto e Trevisani, "podemos ensinar e aprender de inúmeras formas, em todos os momentos, em múltiplos espaços. Híbrido é um conceito rico, apropriado e complicado" (2015, p. 27). Pensando na experiência de RA, essa definição se torna pertinente, pois enriquece e detalha o conteúdo escrito, muitas vezes em preto e branco, transpondo-o para uma versão digital, colorida e interativa, fator que leva 0 aluno a sair da sua zona de conforto, tornando-o atuante no processo de aprendizagem.

A RA, no âmbito da proposta que desenvolvemos, busca instigar o aluno a um aprofundamento teórico, emergindo nos detalhes mais significativos e próximos do real e, segundo Nakamoto, Carrijo, Carsodo, Lima e Lopes, "conjugando realidade com virtualidade" (2012, p. 610).

Atualmente, existem muitos artigos sobre RA na área de Ciência da Computação e Informática que orientam como desenvolver a integração do mundo real e elementos virtuais criados pelo computador. Zorzal, Cardoso e Kirner nos alertam que

[...] a maior parte dos trabalhos desenvolvidos ainda direciona o foco apenas para o aumento da sensação visual, porém são encontrados trabalhos aplicados aos outros sentidos (tato, audição, etc.), com resultados tão bons quanto os obtidos através da sensação visual. (2011, p. 135).

A sinalização desse importante autor nos faz refletir sobre o fato de que ainda necessitamos evoluir muito na área da educação e que, cada vez mais, precisamos criar equipes multidisciplinares, de modo a desenvolver objetos de aprendizagem com realidade aumentada. A RA na educação é representada como o futuro do conteúdo criativo e flexível, pois torna possível a aplicação da teoria para a prática, dando "vida", através de movimentos e imagens, àquilo que, no papel, é estático. Consideramos que o relato deste artigo vem complementar as pesquisas já existentes na área da computação, tendo um viés educacional que busca mostrar o quanto a tecnologia através da RA pode auxiliar o aluno a aprender conteúdos mais complexos, de maneira prazerosa e significativa.

\section{DESENVOLVENDO A REALIDADE AUMENTADA}


Sabemos que, para o desenvolvimento de projetos que envolvam tecnologia, o levantamento de requisitos e as definições de etapas são primordiais para o seu sucesso. Segundo Zamora e Ricaurte, cinco fases são essenciais: "conceptualización, diseño, producción, publicación y control de calidad, cada una con sus respectivas actividades y especificación de resultados" (2017, p. 8). Buscamos, durante o nosso desenvolvimento, contemplar todas estas etapas indicadas pelos autores. Nesse contexto, a descrição a seguir procura apresentar os desafios que enfrentamos e como desenhamos o nosso processo.

Para a inserção de Realidade Aumentada no livro Avaliação Nutricional Aplicada, julgamos ser necessário estabelecer macroetapas no processo de produção. A partir dessas etapas principais, foram desmembradas microetapas correspondentes às responsabilidades dos seguintes profissionais envolvidos no projeto: gestor do projeto, designer instrucional, programador, designer gráfico, editor e revisor técnico. O fluxograma a seguir apresenta as macroetapas. Em seguida, relatamos como cada uma delas foi executada, abordando os aspectos relativos ao seu desenvolvimento que consideramos mais relevantes.

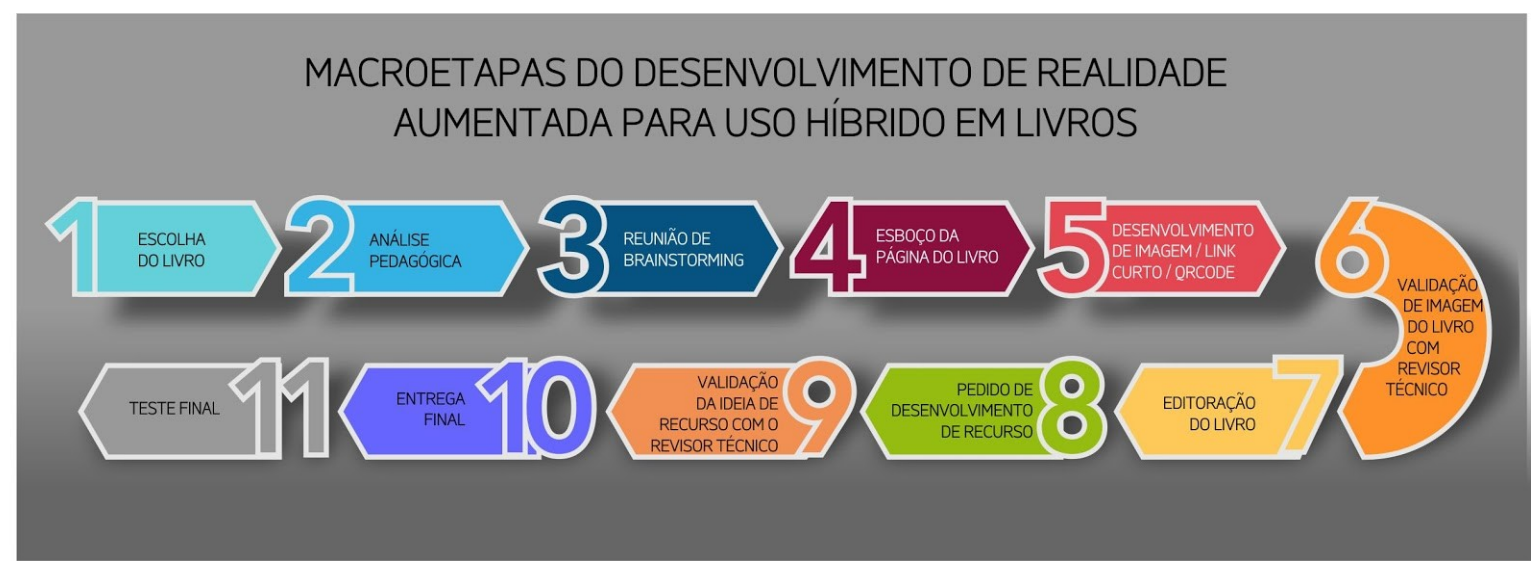

\section{Escolha do livro}

O início do projeto de Realidade Aumentada deu-se com a escolha da área do conhecimento a ser contemplada com o recurso e, especificamente, com o livro a ser usado. O critério inicial foi selecionar livros em que os conteúdos tratados, para serem entendidos de forma mais concreta pelo aluno, demandassem elementos não contemplados somente com texto e imagens bidimensionais.

Mediante esse critério, foram analisados livros das áreas de Arquitetura e Engenharia e Saúde, optando-se pelo livro Avaliação Nutricional Aplicada, do curso de nutrição, pela complexidade de apresentação de alguns conteúdos que, através da RA, poderiam ser introduzidos de maneira mais contextualizada no processo de aprendizagem. Essa 
etapa contou com o envolvimento do profissional designer instrucional, responsável por relacionar o objetivo pedagógico à forma de exposição do conteúdo; e com o editor, profissional responsável pela produção do livro impresso.

\section{Análise didática do livro}

Ao analisarmos o livro, percebemos que, em alguns pontos, a explicação somente textual produzia uma ideia abstrata do funcionamento dos órgãos humanos. Desse modo, verificamos que se tratava de conteúdos importantes que poderiam ser apresentados com o uso da RA, pois o recurso traria concretude a esses órgãos. $A$ transformação em imagens tridimensionais - algumas com interatividade e movimento permitiria que algumas características, tais como movimento dos órgãos e texturas, fossem apresentadas de forma bastante aproximada do real, diminuindo assim a necessidade de abstração por parte do aluno. Mediante essa conclusão, escolhemos utilizar o RA para mostrar o bombeamento do coração, o sistema digestório, o funcionamento da articulação temporomandibular e o músculo adutor.

\section{Reunião de brainstorming}

Escolhidos os conteúdos a serem trabalhados com o uso de RA, reunimo-nos com a equipe multidisciplinar e uma professora da área de anatomia. A docente, cuja função denominamos revisora técnica, teve o papel de orientar a equipe de programadores e designers gráficos quanto ao funcionamento e à aparência dos órgãos do corpo humano.

\section{Esboço da página do livro}

A partir da orientação da revisora técnica, a equipe de programadores e designers gráficos partiram para a modelagem tridimensional dos órgãos e para o planejamento de como esses órgãos seriam mostrados ao aluno. Paralelamente a isso, o designer instrucional, juntamente com o editor, dedicou-se a pensar a alteração na página do livro. Para essa alteração, foi necessário escolher as imagens que seriam as "âncoras" as quais forneceriam acesso à RA. De modo a haver uma integração entre essas imagens mostradas no livro e o recurso de RA, optamos por mostrar sempre o exterior do órgão no livro, ficando a cargo da RA a representação da anatomia interna. Nessa etapa, retiramos do livro as narrativas que detalhavam o funcionamento dos órgãos, tendo em vista que essa função foi passada para o recurso de RA.

\section{Desenvolvimento de imagem, link curto e QR Code}


Na proposta desenvolvida, para o aluno visualizar a RA, é necessário que ele baixe um aplicativo, por meio do site da empresa de soluções educacionais. Como estratégia, criamos uma página de aterrissagem, para a qual o aluno é direcionado ao digitar, em um browser, um link curto, ou ao apontar para um QR Code que acompanha a imagemâncora no livro.

Sendo assim, uma das etapas de execução do projeto foi a validação da imagem final que apareceria no livro, bem como o desenvolvimento de um link curto e de um QR Code.

\section{Editoração do livro}

Validadas as imagens e tendo em mãos o link curto e o QR Code, o editor partiu para a alteração final da página do livro, em software específico dessa área. Em seguida, antes da impressão da totalidade dos exemplares, foi realizado um teste de impressão pela equipe de programadores, com o intuito de confirmar se as imagens ancoravam devidamente o acesso ao recurso de RA.

\section{Pedido de desenvolvimento e execução}

Nesta etapa, o designer instrucional formalizou, para a equipe de programação e designers gráficos, a demanda necessária, ou seja, especificou qual o objetivo pedagógico a ser alcançado com a Realidade Aumentada. No presente caso, o desenvolvimento deu-se da seguinte forma:

- Bombeamento do coração: modelou-se, em três dimensões, um coração humano e mostrou-se sua vista lateral esquerda. Agregou-se movimento à imagem 3D, permitindo assim que o estudante percebesse como acontece o bombeamento do órgão.

- Músculo adutor: modelou-se o interior de uma mão aberta, mostrando sua anatomia, bem como seus ossos, e destacando, por meio de textura, o músculo adutor.

- Sistema digestório: modelou-se os órgãos do sistema digestório que estavam relacionados ao conteúdo exposto no capítulo do livro. O objetivo pedagógico foi mostrar para o aluno a disposição dos órgãos internos presentes na cavidade torácica e abdominal. Para facilitar esse entendimento, criou-se um menu interativo, o qual propiciou que cada órgão fosse mostrado separadamente.

- Articulação temporomandibular: com o intuito de apresentar o funcionamento do aparelho temporomandibular, modelou-se em 3D os ossos da região e deu-se 
movimento à mandíbula. Além disso, o recurso permitiu a aproximação e afastamento da imagem.

\section{Validação do recurso de Realidade Aumentada com o Revisor Técnico}

Após a equipe de desenvolvimento ter modelado os órgãos e atribuído a eles os movimentos e a interatividade, o revisor técnico, no caso uma professora de anatomia, analisou tecnicamente a produção. A profissional apontou algumas incorreções, tais como: cor dos ossos da mão (julgados como muito metalizados), direção das fibras do músculo adutor, movimento acelerado do coração humano, direção do bombeamento do coração, entre outros.

\section{Entrega final / Teste final / Validação final}

À análise do Revisor Técnico, seguiram-se rápidas etapas de validação final:

- O programador e os designers gráficos fizeram os ajustes apontados pela revisora técnica.

- O designer instrucional retomou os testes de impressão das páginas do livro e testou o recurso. Além disso, também fez o download do aplicativo de RA nas páginas da Apple e Google Play para se certificar do funcionamento correto da ação que seria realizada pelo estudante.

- O Revisor Técnico validou tecnicamente o funcionamento dos órgãos humanos após terem sido feitos os ajustes solicitados.

A seguir, na Figura 1, apresentamos o resultado final do desenvolvimento de Realidade Aumentada e a sua integração com o livro impresso:

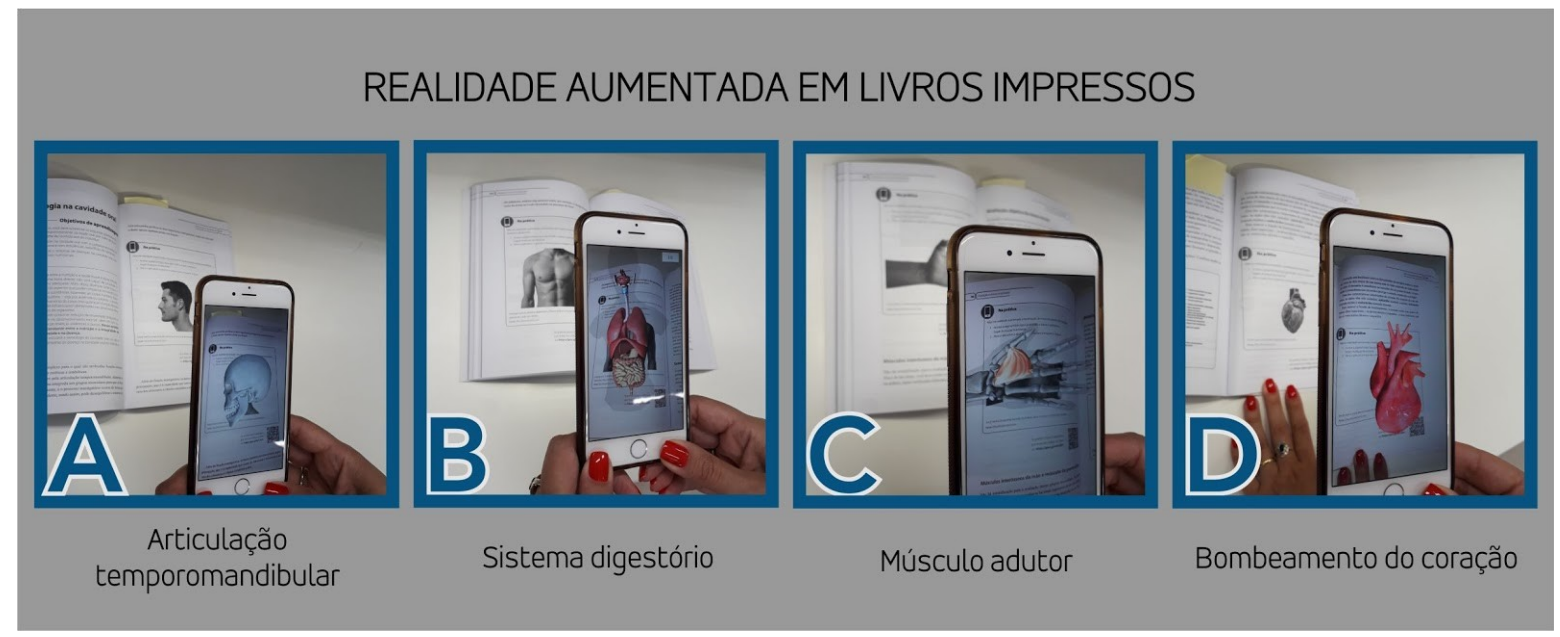


Figura 1. Órgãos humanos sendo mostrados em Realidade Aumentada.

\section{O DESAFIO CONTINUA}

"Os processos de aprendizagem são múltiplos, contínuos, híbridos, formais, informais, organizados e abertos, intencionais e não intencionais" (BACICH e MORAM, 2018, p. 3). Acreditamos que a RA pode contribuir para muitos destes processos, através do apoio, da aplicabilidade e da proximidade ao "real" que são oferecidas ao aluno.

Nossas considerações finais convidam o leitor a pensar no grande desafio de continuar desenvolvendo a RA para contextos educacionais, envolvendo equipes multidisciplinares que busquem integrar conceitos tecnológicos a aspectos pedagógicos que visem a buscar as melhores maneiras de proporcionar a aprendizagem aos alunos. A inquietação que nos desacomodou ao longo do desenvolvimento desse projeto diz respeito àqueles alunos que ainda possuem baixo acesso à internet, seja por restrições financeiras ou por questões geográficas. Apesar dessa dificuldade, esperamos que esses estudantes consigam acessar o nosso aplicativo de RA.

De modo geral, este artigo, além de mostrar o processo de desenvolvimento da RA que, de modo aparentemente sutil, parece ser fácil quando se pode contar com uma equipe multidisciplinar -, permitiu vislumbrar também as inúmeras possibilidades tecnológicas contemporâneas a que temos acesso, bem como as dificuldades que podem surgir durante o desenvolvimento e a possibilidade de projetarmos o futuro da aprendizagem de maneira mais prazerosa e próxima do real.

\section{REFERÊNCIAS}

BACICH, Lilian; NETO, Adolfo T. e TREVISANI, Fernando M. Ensino Híbrido. Personalização e tecnologia na educação. Porto Alegre: Penso, 2015.

MORAN, José (Orgs.). Metodologias ativas para uma educação inovadora. Uma abordagem teórico-prática. Porto Alegre: Penso, 2018.

NAKAMOTO, Paula T.; CARRIJO, Gilberto A.; CARDOSO, Alexandre; LIMA, Lázaro V. O.; LOPES, Ederaldo J. Estratégias de engenharia de requisitos para ambientes de realidade aumentada. JISTEM, Brazil, v. 9, n. 3, p. 607-626, set./dez. 2012.

SCHLEMMER, Eliane. Gamificação em espaços de convivência híbridos e multimodais: design e cognição em discussão. Educação e Contemporaneidade, Salvador, v. 23, n. 
42, p. 73-89, jul./dez. 2014.

ZABALA, Antoni e ARNAU, Laia. Como aprender e ensinar competências. Porto Alegre: Artmed, 2010.

ZAMORA, Leonardo. B., RICAURTE, Javier A. B. Metodología para la construcción de objetos virtuales de aprendizaje, apoyada en realidad aumentada. Sophia, Colombia, v. 13, p. 4-12, jan./fev. 2017.

ZORZAL, Ezequiel; CARDOSO, Alexandre e KIRNER, Claudio. Aplicações adaptativas de visualização de informações com realidade aumentada. Sociedade Brasileira de Computação, João Pessoa, 2011. Livro do pré-simpósio, IX Symposium on Virtual and Augmented Reality. Editora SBC, Minas Gerais. 